\title{
Visualizing a Calculus of Recovery: Calibrating Relations in an Opioid Epicenter
}

\author{
Sydney M. Silverstein ${ }^{1}$ (D) Katie Milligan ${ }^{2} \cdot$ \\ Annette Osborn ${ }^{2}$ Iman Aamir ${ }^{2}$ Danielle Gainer ${ }^{1,3}$. \\ Raminta Daniulaityte ${ }^{4}$
}

Accepted: 25 October 2021/Published online: 20 November 2021

(C) The Author(s), under exclusive licence to Springer Science+Business Media, LLC, part of Springer Nature 2021

\begin{abstract}
This article uses participatory photography to explore the relationships animating efforts towards recovery from opioid use disorder (OUD) in the Dayton, Ohio area, an epicenter of illicit opioid use and overdose death. A photo-elicitation project was conducted with thirteen people who met the DSM-5 criteria for OUD. Photographs were used as prompts during qualitative interviews, which were thematically analyzed. Analysis of both visual and textual data demonstrated the ways in which recovery became an unfolding process of calculation as participants made strategic choices to navigate relations and encounters with things, people, and places. Relationships across each of these domains could, under some circumstances, serve as supports or motivators in the recovery process, but, in alternate settings, be experienced as "triggers" prompting a resumption of problematic drug use or, at the very least, a reckoning with the feelings and emotions associated with painful or problematic aspects of personal histories and drug use experiences. Findings highlight the importance of understanding recovery as a calibration of the ambiguous relations animating experiences of everyday life. We argue for continued emphasis on recovery as an active performance and ongoing practice of
\end{abstract}

Sydney M. Silverstein

sydney.silverstein@wright.edu

1 Center for Interventions, Treatment, and Addictions Research, Department of Population and Public Health Sciences, Boonshoft School of Medicine, Wright State University, 2555 University Blvd., Suite 200, Dayton, OH 45324, USA

2 Mount Holyoke College, 50 College Street, South Hadley, MA 01075, USA

3 Department of Psychiatry, Boonshoft School of Medicine, Wright State University, 2555 University Blvd., Suite 100, Dayton, OH 45324, USA

4 College of Health Solutions, Arizona State University, 425 N 5th Street, Arizona Biomedical Collaborative Room 121, Phoenix, AZ 85004, USA 
calculation - of risks and benefits, of supports and triggers, of gratification and heartbreak-rather than a goal or static state.

Keywords Opioids · Addiction · Recovery · Photo-elicitation ·

Participatory photography

\section{Introduction}

Vivian began by admitting that she had relapsed. She stopped taking her buprenorphine pills, and was now using heroin again, every day. She wanted to get back on her medication but did not want to go through the initial phase of detoxification in front of her two-year old son, whom she cared for full time. She began to talk about the pictures printed out in front of her. "This right here is a drug screen," she began, pointing to one of the images. "This is two months ago. I had relapsed again just for like, that one freaking moment and it's all it takes, is one moment. I was positive for everything."

The pictures that Vivian had taken formed the subject of a photo-elicitation interview, a component of a longitudinal study in which she had been enrolled for nearly 2 years. The study followed the lives of people with opioid use disorder (OUD), who were interviewed every 6 months about drug use, self-treatment, and treatment seeking practices. Vivian's recent relapse came after nearly 3 years of avoiding heroin and other illicit opioids and adhering to a treatment regime of buprenorphine pharmacotherapy and counseling services. She offered the following explanation for her relapse: "[J]ust life in general. It's just part of being an addict." But Vivian's photographs offered more context than this. In addition to her drug screen, the images in her collage included, among other things, a Christmas tree, a single pink rose, a stack of outstanding bills, a pile of her son's toys and a totaled car. 'Life in general,' it seemed, was an assembly of relations with objects, people, and places that together shaped the trajectory of her addiction, and her attempts at recovery.

In the Midwestern United States, where this study is based, cycles in and out of opioid use, such as that described by Vivian, have become even more perilous. They come at a particular historical conjuncture when opioid use has become not only widespread due to over-prescription of pharmaceutical opioids, but also exceptionally lethal due to the saturation of local drug supplies with illicit fentanyl and fentanyl analogues (Ciccarone 2019; Volkow 2021). But the risk of overdose death is hardly the only factor that must be navigated by people who use illicit opioids. Indeed, the management of addiction is complex and multifaceted.

The brain disease model promoted by the National Institute on Drug Abuse (NIDA) defines addiction as "a chronic disease characterized by drug seeking and use that is compulsive, or difficult to control, despite harmful consequences" (NIDA 2018b). This definition is frequently operationalized through the American Psychiatric Association's Diagnostic and Statistical Manual, 5th Edition (DSM-5), which includes a set of criteria used to help identify patterns of behavior that have become so problematic in nature that it interferes with an individual's functioning 
(APA 2013). While NIDA's neurobiological understanding of addiction has been crucial in advancing pharmacotherapeutic interventions and advocacy for people experiencing problematic substance use (Koob and Volkow 2016), it can nevertheless be internalized by people such as Vivian who understand their chronic relapse as "just part of being an addict"" (Garcia 2010). As Vivian's collages suggest, addiction is never only about the relationship between an individual and a substance, but rather a more expansive set of relationships that can both shape desires to stop using drugs and make it difficult to do so.

Attention to context is becoming more widespread in addiction research. Recently, NIDA has begun to situate the neurobiological model of addiction within social and environmental milieus, advocating for a biopsychosocial model that recognizes the "complex interactions between biology, behavior, and environment" (Volkow 2018). The biopsychosocial model is in line with findings from social scientists from several disciplines, who have shown how epidemics of drug use are produced at particular times and places, and among certain people more than others (Agar 2003; Agar and Reisinger 2001; Bourgois 2003). Context not only shapes the epidemiology of illicit drug use, but also experiences of it (Duff 2012; Zinberg 1984). Moreover, addiction must be contextualized within local frameworks of meaning, mapping on to chronic experiences of dispossession (Garcia 2010) and postindustrial decline and dislocation (Draus, Roddy, Greenwald 2010; Hansen 2018) as well as experiences of structural marginalization amidst gentrification and urban renewal (Bourgois and Schonberg 2009; Rui 2014).

Just as context matters in experiences of problematic drug use, it also plays a key role in treatment of and, ultimately, experiences of recovery from addiction. Recovery is a process with fits and starts (Kougiali et al. 2017), and is situated within the particular conditions in which it unfolds (Ashford et al. 2019). Yet much research on recovery has focused on studying the contexts in which people who already consider themselves to be 'recovered,' are able to successfully abstain from problematic drug use for a substantial part of time. This research has been crucial in highlighting the importance of networks of social support in recovery (Best et al. 2012; Granfield and Cloud 1999; Neale and Stevenson 2015), aiding a burgeoning movement to establish more holistic systems of addiction treatment and recovery support, such as treatment ecosystems or recovery-oriented systems of care (Ashford et al. 2019; Winhusen et al. 2020), however, it has tended to overlook the more faltering aspects of journeys towards recovery, and the liminal, often times back-and-forth period between active drug use and cessation. Closer, ethnographic attention to the betwixt-and-between is crucial, as it represents a highly malleable period, as subjects become both more open to forms of support and intervention, but also more vulnerable to feelings of failure and disappointment, and even overdose death (Fast 2017; Garcia 2010).

To engage ethnographically and sensorily with this liminal period, we use participatory photography to explore how recovery is experienced and negotiated in

\footnotetext{
${ }^{1}$ While we use the term "addiction" throughout this paper, we do so with what Garriot and Raikhel have described as a "critical ambivalence to the individualizing, internalizing, and pathologizing logics of the addiction concept" (2015:479).
} 
daily life by people not yet recovered from OUD, but somewhere in the process of becoming. We apply a critical-phenomenological approach to analyzing both visual and qualitative data, to generate a situated understanding of recovery as an unfolding experience grounded in everyday encounters. Informed by STS scholarship that outlines a more expansive notion of the social, our attention to these encounters includes relations with people, but also places and objects. Closely attending to these relations demonstrates how attempts to cease or mitigate problematic drug use-or recover from an SUD_involve an active calibration of the ambiguous relations animating experiences of everyday life. We argue for a more acute emphasis on recovery as a calculus - an active performance and ongoing practice of calculation of risks and benefits, of supports and triggers, and gratification and heartbreak-rather than a goal or static state.

\section{Background}

\section{Defining Recovery}

Like addiction and addiction treatment, recovery is defined in different ways for different people (White 2007). Most broadly, it is characterized as a process of change in which people improve their health and well-being through the control or cessation of problematic substance use and related behaviors (Ashford et al. 2019; NIDA 2018a; SAMHSA 2016). Yet debates surrounding how to define recovery are enacted across different contexts, with some treatment programs or support groups insisting on measures of abstinence or sobriety, and others emphasizing a more inclusive message of positive change that may or may not include some use of substances or pharmacotherapy (Ashford et al. 2019; White 2007).

In the Dayton, Ohio metropolitan area, where this study is set, successive years of high overdose mortality rates coupled with Ohio's expansion of Medicaid services in 2015 have helped to create an broad landscape of treatment and support options for people struggling with SUD (Goodnough 2018; Silverstein et al. 2020). Multiple modalities of addiction treatment are available, including detoxification, community based correctional facilities, residential treatment settings, therapeutic communities, "cash-only" clinics, and multidisciplinary intensive outpatient programs which offer pharmacotherapies with methadone, buprenorphine, or an extended-release naltrexone (Vivitrol ${ }^{\circledR}$ ) injection (MCADAMHS 2021). Self-help groups such as Alcoholics Anonymous (AA) and, to a lesser extent, Narcotics Anonymous (NA), as well as the faith-based recovery support group Celebrate Recovery host meetings across Dayton every day of the week, and local recovery ministries offer support groups, yoga classes, and craft nights. In light of the acuteness of the local overdose death crisis (Dayton's home county of Montgomery had one of the highest overdose death rates in the country in 2017 (Rossen 2019)), there is growing acceptance of an expansive definition of recovery that includes philosophies that emphasize abstinence, ones that support the use of pharmacotherapies, and even harm reduction approaches, although stigma against pharmacotherapies as a "crutch" and harm reduction approaches as "enabling" persist throughout the community. 
A growing body of qualitative and ethnographic scholarship across the social sciences has attempted make sense of what these diverse notions of recovery from an SUD look like from an emic perspective. Key works in studies of recovery from SUD have explored how people in recovery navigate everyday life (Neale et al. 2012), creating new modes of being and forms of sociality in the wake of problematic drug use (Biernacki 1986; Granfield and Cloud 1999). Some of these works have emphasized the importance of social networks (Best et al. 2011; Best et al. 2012; Granfield and Cloud 1999; Neale et al. 2014) or transformative narratives (Linde 2000; McIntosh and McKeganey 2000) to help understand the multiple components (everyday practice, social relationships, performance of self) that constitute the active practice of living in recovery. Other work has explored the subjective experiences of people in recovery, focusing on the tenuous nature of periods of progress. Angela García's sustained ethnographic work with people who use heroin in Northern New Mexico, for instance, offers one of the most detailed and nuanced perspectives on recovery as a process unfolding through time (Garcia 2008, 2010). García's account of Alma, whom she meets during a stint at an inpatient detox facility, and follows through ebbs and flows of heroin use, religious involvement, and ultimately death from overdose, highlights the fragile nature of recovery, as well as critiques of the concept itself by individuals such as Alma, who question if there is always something to recover, given local historical experiences of dispossession and loss.

While García's work emphasizes the fragility of recovery, however, much of the scholarship on recovery has attempted to determine what makes for a successful recovery-using now-abstinent and/or treatment compliant individuals as a demographic of study. Social scientists Robert Granfield and William Cloud, for instance, developed the concept of recovery capital, which they define as "critical elements that an individual possesses or that exist within his or her immediate surroundings and that function to promote and sustain a recovery experience" (Granfield and Cloud 1999:179). Granfield and Cloud argue that the neurobiological model of addiction generates interventions that rely too heavily on notions of individual will and agency characteristic of neoliberal notions of subjecthood. They argue, in contrast, that addiction arises out of meaningful encounters between people and psychoactive substances, as well as the social worlds of alcohol and other drugs. Rather than an emphasis on abstinence, recovery should be oriented towards the creation of new interpersonal relationships that create a scaffold of meaning to support a transition away from problematic consumption.

The concept of recovery capital is helpful for understanding the interpersonal nature of both addiction and recovery. However, its focus on interpersonal relationships and forms of capital obfuscates some of the other types of relations that come to matter in a recovery process. By evaluating recovery through forms of capital, too much emphasis may be placed on what is able to be assessed (definable resources such as housing, money, social networks), ignoring some of the less visible yet daily interfaces with the surrounding world that can affectively shape how people navigate resources available to them, or whether they even want to do so. In other words, while forms of capital may indicate a proclivity towards particular outcomes in a recovery trajectory, they do little to illuminate what it feels 
like along the way, and how this trajectory must interface with memories and associations from the past, in addition to aspirations for the future (cf. Fast 2017).

A more expansive emphasis on relations beyond what can be assessed as forms of capital (or even negative capital) is crucial to understanding the liminal period of becoming that proceeds any experience of recovery from SUD. Indeed, within the self-help community, there is an adage that people in recovery from SUD should stay away from "people, places, and things" that could serve as triggers for problematic consumption of alcohol and other drugs (Nowinski et al. 1992:75). Similarly, cognitive behavioral therapy (CBT), a common modality of SUD treatment (Magill and Ray 2009), utilizes operant conditioning theory and involves actively identifying and avoiding triggers associated with previous substance use while replacing them with more positive reinforcing "people, places and things" (McHugh et al. 2010). These conceptualizations reveal an ontological position like those coming from science and technology (STS) scholars who draw on a framework of actor-networks to explain how both people but also conditions, such as SUDs, are not sui generis entities, but rather emergent from human and morethan-human relationships (Latour 2005; Mol 2002, 2010) through which people construct their worlds and assemble meaning (Latour 2005; Törrönen and Tigerstedt 2018). For instance, sociologist Fay Dennis has argued that "triggers" (cue-induced cravings) for drug use are "a kind of intangible force that exist explicitly in relationships between or in excess of human and nonhuman entities (bringing about certain actions like using drugs" (Dennis 2016:129, emphasis our own). Following scholars, such as Dennis, who have emphasized the role of more-than-human relationships in shaping experiences of substance use-what Cameron Duff has called "posthuman turn for research on the consumption of alcohol and other drugs" (Duff 2012:146)—we argue here that the relationships that shape and help determine a recovery trajectory are relationships with people, but also places and objects. A research practice including participatory photography, a collaborative practice of knowledge production, illuminates the importance of the relational nature of recovery, and the calculations emergent at the interfaces of subjects and their relations with other people, places, and things.

\section{Visualizing a Calculus of Recovery}

Participatory visual research methods offer a promising direction for generating a mutual understanding of sensory experiences of social worlds (Franzen and Orr 2016; Silverstein 2021) and imaginaries (Fast 2017; Graham 2016; Silverstein 2017). Participatory visual methods also suggest strategies for navegating the complex dynamics of representation involved in research with vulnerable populations in order document and explain relations that they encounter and find meaningful (Bukowski and Buetow 2011; Fast 2017). In prior studies, participatory photography has been used to understand emic perspectives on addiction (Abadie et al. 2018; Padilla et al. 2019; Syvertsen et al. 2017), as well as recovery from other forms of illness (Cabassa et al. 2013; Mizock et al. 2014). However, to our knowledge, no studies have used participatory photography to specifically explore attempts at, and experiences of recovery from SUD. In attempting to theorize a 
hard-to-define and highly contested notion such as recovery, critical work with participatory images sheds light on how recovery becomes entangled in everyday relations.

A more expansive notion of social relationships helps to reframe the experiences of people seeking to disentangle themselves from problematic opioid use. Navigating a vibrant world (Bennett 2010) as a person in recovery creates complex sets of choices and dilemmas that are always vulnerable to the introduction of novel elements and the affects that emerge from contact with them. Rather than something that can be assessed in the terms of a particular outcome (say, years of abstinence from illicit drug use), we follow scholars such as Duff (2016) and Lester (2013) in understanding recovery to be something fluid and constantly unfolding, and always contingent with relations among people, places, and things. Following this relational emphasis, we understand recovery not as a process whose success is contingent on forms of capital, but as a calculus, or active logic that guides how people navigate relations and encounters considering anticipated impacts on their desires to use drugs, or ability to do so. In the context of recovery, calculus, defined by Oxford Dictionary as "a particular method or system of calculation or reasoning," is an ongoing process of weighing of the impacts of unfolding social, geographic, and material relations as they come to impact recovery trajectories. In other words, to consider recovery more carefully as an active process and not an outcome is to attend more closely to how recovery, or aspirations of recovery, are present in the choices and logics that guide the practices of everyday life.

To understand how people living with OUD calculate recovery through practices of daily life, we apply a critical-phenomenological approach to analyzing our materials, which include both photographs and interview transcripts, as well as notes from the first author's sustained ethnographic engagement with the community. Our blended approach is particularly useful for understanding the experiences of people who use drugs, whose life experiences, while rich and multifaceted, are nevertheless shaped by the structural and interpersonal forms of violence that disproportionately impact people living with an illness that is criminalized (Bourgois and Schonberg 2009; Sue 2019). Critical phenomenology emphasizes how the everyday is textured by micro- and macro-level factors that shape the experiential domain, generating valences for otherwise innocuous encounters (Mattingly 2019a, 2019b; Mosteanu 2020). It plays close attention to the relationship between subjective experience and the political-economic factors that create particular fields of experience in particular times and places (Desjarlais 2011). In this manner, our analysis of recovery is phenomenological in its focus on the experiential nature of recovery, yet critical in that we pay close attention to multilevel contexts in which experiences of recovery are tempered by experiences of direct affective and material encounters with objects, people, and places. Thinking critically, phenomenologically, and through images is therefore a means of destabilizing the very notion of "recovery" as a simple and straightforward aspirational status towards which people living with addiction might strive towards (cf. Mattingly 2019b). Thus, our primary aim is to use both photographs and photoelicitation interviews to gain a critical-phenomenological understanding of recovery as it unfolds relationally, made, and remade through calculation. 


\section{Materials and Methods}

\section{Data Collection}

At the time of the interview, all participants in the photo-elicitation were currently enrolled in a longitudinal, mixed-methods study on buprenorphine diversion, selftreatment, and SUD treatment services in the Dayton Metropolitan Area (Daniulaityte et al. 2019). To be eligible for this study, participants had to be at least 18 years of age, live in the Dayton, OH metropolitan area, meet the DSM-5 criteria for moderate-severe opioid use disorder, and self-report use of non-prescribed buprenorphine within the last 6 months. The study was approved by the Wright State University IRB.

Photo-elicitation interviews were conducted between May 2019 and March 2020. Participants were invited to participate in the photo-elicitation exercise during a follow-up interview for the longitudinal study. Participants in the photo-elicitation were selected by the lead author to represent individuals in different places on a recovery trajectory - from individuals who considered themselves to be in recovery from OUD to participants who continued to inject opioids multiple times a day but articulated a desire and sense of readiness for change and were experimenting with strategies to cease or mitigate their drug use (actively contemplating and preparing themselves to make an attempt at recovery). Prior to the photo interview, all participants had been interviewed by the lead author at least once, and up to five times as part of the longitudinal study.

To begin the photo-elicitation exercise, participants were given a handout by the lead author asking them to take a total of 10-12 photos that "illustrate and help express your recovery-related struggles, motivations and successes," including "5-6 photographs that represent or are associated with things, ideas or experiences that motivate or help you in your recovery", and "5-6 photos that represent things/ ideas or experiences that make it difficult for you to stick to recovery goals". The handout specified that participants were to avoid taking identifiable photographs of people. Participants were instructed to send digital photographs to the lead author via cellular phone or Facebook Messenger. Participants who did not have data plans on their phones were given the option of transferring the photos using Bluetooth once in our office. While the lead author was initially concerned that this exercise might exclude participants who did not have access to camera phones, the three participants that did not have phones were able to borrow a phone to complete the activity.

After receiving the photos via text or Messenger, the first author scheduled a follow-up interview, and printed out copies of the photographs before each meeting. During the interview, the photographs were used as prompts for discussion of beliefs and experiences regarding recovery after a brief set of initial questions inquiring about changes in drug use, self-treatment, and treatment seeking patterns since the participant had last been in the office. All interviews were conducted in a private field office, and participants were compensated with a $\$ 40$ check or gift card. To protect confidentiality, pseudonyms are used throughout the manuscript. 


\section{Qualitative Analysis}

Interview transcripts were uploaded into ATLAS.it software, where they were coded by authors $1-4$. We created a first draft of a codebook using key topics discussed in the interview protocol, and in-vivo codes that emerged in a close reading of two transcripts. We used this initial codebook to code two additional interviews, then met as a group to select and define the codes, discussing and agreeing upon inclusion and exclusion criteria for each of our established codes, and examples/ exemplar quotes to illustrate them. We then tested out the initial codebook by recoding the two initial interviews, in addition to two new ones. Each interview was coded twice-once by a primary coder, and once by a secondary coder, who reviewed the coding of the primary person and made note of any questions that emerged in their coding practice. Discrepancies between primary and secondary coders were discussed by the group to ensure consistency of coding approaches. As new themes emerged from the additional interviews, we discussed the addition of further emergent codes, and refined existing codes until saturation was reached. Upon reaching saturation, the remainder of the interviews were divided among authors 1-4 for coding, with each interview assigned a primary and secondary coder.

Once interview transcripts had been coded, authors 1-4 created a preliminary coding schema for the photos, using emergent themes from the interview transcripts used to describe the contents of the images and their relations to the phenomena of recovery. Once an initial coding schema was established, authors 1-4 reviewed a set of photos independently, adding to the coding schema when appropriate. Authors 1-4 then met as a group to discuss and code the photographs. Each photograph was assigned a numerical code, and then discussed by the group, who contextualized its contents within the appropriate sections of transcript text and, when relevant, the caption created by the participant.

Once both textual and visual data had been coded, we used a criticalphenomenological framework to analyze select nodes of coded data that emerged as the most vital articulations of participants' challenges and supports in their experiences of recovery as articulated through the photographs-as-prompts. Sections of coded text relevant to this framework were separated out and explored line by line to identify patterns, associations, concepts and explanations within the data which were then analyzed in relation to existing research, using iterative categorization (Neale 2016). In keeping with a critical-phenomenological approach to recovery and recovery capital, the analysis focused on domains identified as most relevant to articulations of participants' struggles to move their lives in a positive direction, as well as articulations of the factors that encouraged and supported them to do so. Textual analysis was triangulated with photographic data to inform findings. 


\section{Results}

\section{The Sample}

The thirteen participants in the photo-elicitation interviews occupied different spaces on a recovery continuum (see Table 1). Six participants understood themselves to recovering from OUD, although all six had used illicit opioids within the past 18 months and did not consider themselves to be fully established as "recovered". Five of the six received buprenorphine pharmacotherapy, with three getting their buprenorphine from an outpatient treatment program where they also attended group therapy sessions as well as meetings with a prescribing doctor. The other two got their prescription through a primary care physician, although both attended counseling sessions and the occasional self-help (AA or NA) meeting. Only one of the participants who considered herself to be in recovery was not enrolled in a treatment program but was active in the local self-help community and regularly attended support meetings (AA) and had a close relationship with her sponsor.

The remaining seven participants did not consider themselves to be fully in recovery but were invited to participate in the photo-elicitation program because they had, in prior interviews, articulated a desire to begin a recovery process. Some had attempted this by ceasing or mitigating their opioid use, or were currently experimenting with tactics (enrolling in treatment or detox programs, attending selfhelp meetings or attempting to self-treat their OUD with non-prescribed buprenorphine) for doing so (Silverstein et al. 2019, 2020). Four of these participants were using heroin/fentanyl intravenously daily and were not enrolled in any kind of treatment, although two of the four described attending self-help (AA or NA) meetings from time to time. The remaining three participants described more active attempts to mitigate their illicit opioid use and were enrolled in intensive outpatient treatment programs where they received methadone pharmacotherapy, in addition to attending group and individual counseling sessions mandated by their treatment

Table 1 Participants and their drug use/Tx enrollment status

\begin{tabular}{lll}
\hline & Enrolled in treatment & Not enrolled in treatment \\
\hline Using drugs (IV heroin/NPF daily or near daily) & Marco, 35 & Sadie, 32 \\
& Lexie, 34 & Tommy, 36 \\
& Amanda, 24 & Annie, 43 \\
Not using any illicit drugs & & Matt, 42 \\
& Ed, 36 & Nicole, 38 \\
& Jim, 39 & \\
& Vivian, 41 & \\
& Chance, 24 & \\
& Allie, 24 & \\
\hline
\end{tabular}


programs. One of the three (Lexie) also attended self-help meetings and described keeping her AA "Big Book" on hand and reading from it on a regular basis. Despite her daily use of heroin/fentanyl and near-daily use of methamphetamine, she also described a recent mental shift that made her feel ready, mentally, to focus on her recovery, and included in her photo project images of motivational collages and recovery-oriented rap artists that had been helping encourage her on her recovery journey.

\section{The Images}

All thirteen participants submitted a minimum of ten images and a maximum of fifteen. Most participants took photographs using the camera on a cellular phone, although two participants (Vivian and Sadie) created collages with their images, opting to explain elements in the collages rather than individual photos. The images, and subsequent discussions of them, demonstrated the ways in which recovery became an unfolding process of navigating relations and encounters with objects, people, and places. Interviews revealed ways in which relationships across each of these three domains could, under some circumstances, serve as supports or motivators in the recovery process. At the same time, many of these same relationships could, in alternate settings, be experienced as "triggers" prompting a resumption of problematic drug use or, at the very least, a reckoning with the feelings and emotions associated with painful or problematic aspects of personal histories and drug use experiences. As such, we have divided our findings into three sections that address, respectively, how emergent interactions with things, people, and places become calculations and choice that shape attempts to recover from OUD.

\section{Things}

Mementos and everyday objects were the most frequent subject of photographs. Mementos often represented social relationships and stood in for photographs of loved ones that the participant was unable to take due to ethical concerns or estrangement and are thus discussed in the following section (on interpersonal relationships). Everyday objects, however, represented a far more diverse nexus of relations. In analyzing our photographic data, we coded mementos, medicines, drug paraphernalia, and everyday objects separately. In this section, however, we discuss them together. Our decision to do this is informed by STS perspectives that emphasize affective encounters with materials in constructing worlds and assembling meaning (Latour 2005), as well as a common thread of ambivalence that ran throughout discussions of meaningful things. While the significance of things such as medicines and paraphernalia may seem overdetermined in the context of people living with addiction, discussions of these images emphasize diverse affective encounters with these objects, and the roles of these encounters, or the anticipation of them, in shaping a recovery calculus.

Images of medicines-specifically OUD pharmacotherapies buprenorphine and methadone, as well as psychiatric medications, were largely described by 
participants as things that supported them in their recovery. While pictured in an overall positive manner, however, medication regimens as well as the clinical encounters necessary to obtain them were discussed with greater ambivalence. Take Marco, who used one hand to snap a picture of himself receiving his morning dose of methadone from the clinic, where he was required to show up six days a week to receive his daily dosage (Fig. 1):

When you don't have that [methadone] every day...the amount of stress and despair and depression...there's a heavy, heavy weight on you [...] I know I can go to the clinic and get my drink every day. I'm cool. If you don't have that, you've gotta' scheme, you've gotta' steal, you gotta' plot, you gotta' depend on, it's very rare that you can work for your dope money.

Despite his praise of his daily dose of methadone, Marco frequently injected fentanyl in the afternoons, following his visit to the clinic. He explained that he used for emotional reasons, but also that, for him, the clinic was "a big trigger" because "everybody there...uses dope and just use that [methadone] as their get well and get high on top of it." For Marco, methadone was helpful, lifesaving even, but it was also articulated as grounds for encounters with people and feelings associated with drug use. His continued adherence to a regime of methadone pharmacotherapy, then, was the result of his calculation that the relief and security promised by his daily dosage of methadone was more important than his encounter with the "big trigger" of the methadone clinic. In other words, while he was sometimes frustrated with his continued use of heroin/NPF despite his attempts to cease or mitigate his use of these drugs by enrolling in methadone pharmacotherapy, this sense of disappointment was preferable to the profound fear and panic that opioid withdrawal instilled in him. To transition to full abstinence from heroin/NPF,

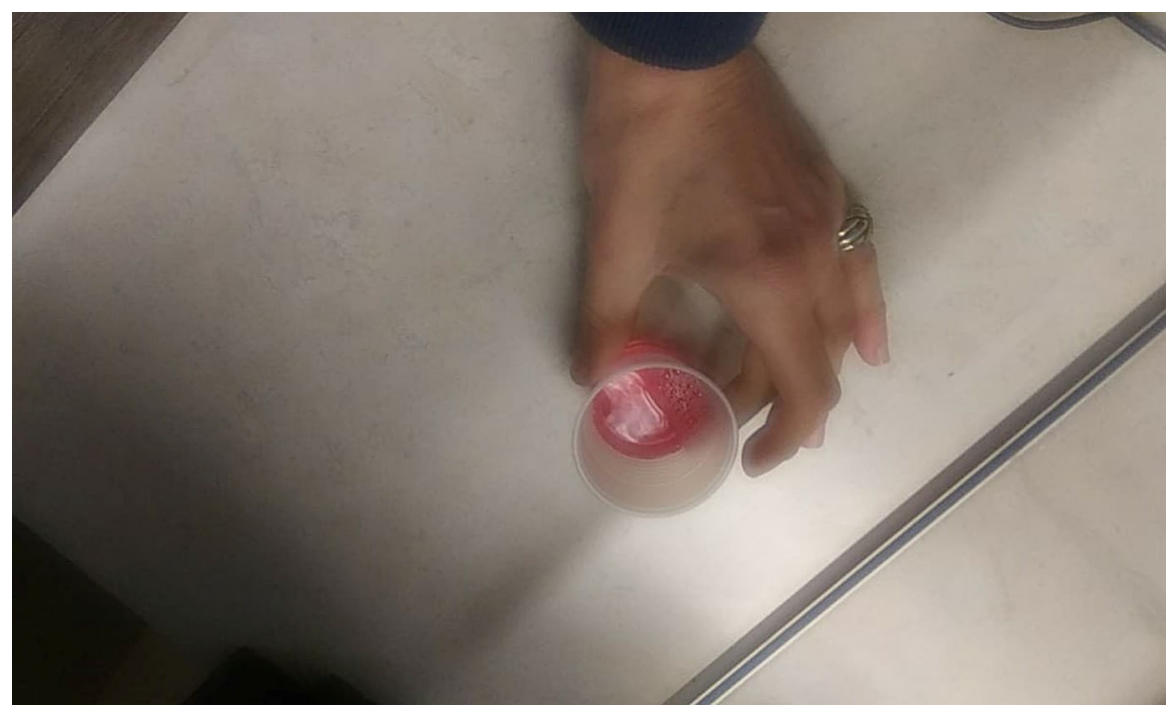

Fig. 1 Marco: "The best damn bartender in the world" 
Marco acknowledged that he would probably have to leave the methadone clinic, giving up his helpful relationship with a thing (methadone) to free himself from the problematic relationship with a place (the clinic). However, he emphasis on the relief and stability offered by the methadone clinic and its offerings was an acknowledgement that moving away from its "triggering" environment would leave him vulnerable to a range of uncomfortable feelings and situations he was not yet ready to face. This was a choice he made and recognized, a calculus that shaped the pace and trajectory of his recovery, and maintained him in a liminal state, stabilized on methadone but still connected socially and materially to heroin.

While medicines and their accompanying assemblage of places and associations could inspire ambivalence, other objects were presented as more steadfast anchors in the recovery process. Jim's image of pile of bracelets that he had made in his VAsponsored treatment program was one such example. He referred to them as "survival bracelets," and described how he was taught how to make them as a tactic for managing urges to use drugs.

So, they said that when you have an urge, just make a bracelet and by the time that you're done with it your urge will be over. And I really, really understood that because when I ended up with a hundred of these things just in a box, you know, I have something to show for everything...for every urge that I had. Instead of a fine or a jail sentence I just got a bracelet.

Displayed in his home, the bracelets reminded Jim that he had beat back urges before. Passing by the bracelets, stored on his shelf, could also serve as a cue towards a set of materials and practices that Jim could employ to help him manage future incidences of distress, a calculation of time and desire (Fig. 2).

Unplanned encounters with objects could redirect a moment. In some scenarios, such as Jim passing by his survival bracelets, objects served as linkages to new projects of self-making forged out of recovery experiences. But objects also served

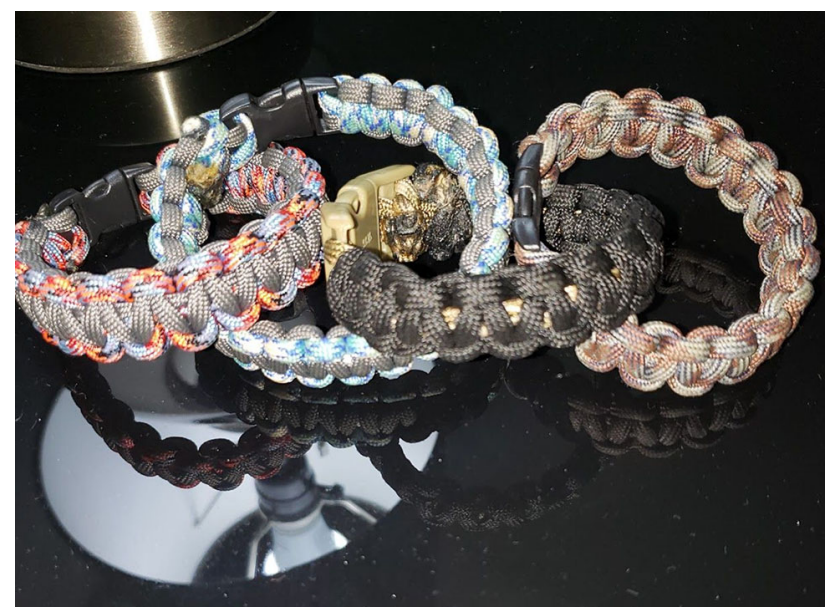

Fig. 2 Jim: "When I have urges, I try to make something with the energy instead of using." 
as portals into more problematic networks of relations between participants and the social worlds of drug use in which they had been, or still were entangled. Needles, lighters, and drug baggies formed the subject of a number of photographs and were described as triggering a physical sensation that recalled not simply a desire to use heroin, but embodied memories of collecting these found and discarded objects during moments of desperation (recalls Tommy, while speaking of his photograph of a syringe that he found in the grass at a nearby public park, "I didn't have a needle, I was sick as fuck and when I looked down there was one so I said "fuck it". I used some bleach to clean it-tried to clean it as best as I could.").

However, forms of drug paraphernalia were not the only objects understood to be pregnant with meaning and "triggering" associations for participants. Perhaps most striking were images of seemingly innocuous, everyday objects whose meaning shifted in the context of an unfolding experience of recovery. Jim, for instance, included a photograph of six dollars, cash, sitting on his coffee table. He captioned the photo "extra cash + idle time $=$ relapse". Jim's explanation of the relations between money, time, space, and risk in his recovery are worth quoting at length:

I rarely keep cash on me...but $\$ 6$ is enough to kill someone, you know? So, I try not to even carry it. [...] It would just start with a bag of fentanyl, and it's usually $\$ 10$ but if you have $\$ 6$, they'll probably take it and give you something, and with cash I still, in a way, look at things in terms of dope. When I first got my apartment, I had just gotten out of treatment, and I had gotten a bunch of money from my settlement thing at the VA [dept. of Veteran's Affairs]. As I was buying things, I was thinking about... do I get this or the cheaper one? Well, I should probably get the more expensive one because I can get more dope for it. It's just an instant thought how much dope could I trade this for when I am down? I was looking at my stuff like my savings account for my next explosion...I was planning a relapse before it even happened.

Explaining his photograph, Jim reveals the complex calculations involved in navigating the world as a person in recovery, where proximities of money and people, or valuable objects, idle time, and cravings needed to be always calibrated to avoid the "next explosion". Even if he set out with the best intentions-to study at the library or see a counselor at the VA-unpredictable elements in his life could leave him vulnerable, with cash in his pocket creating fertile grounds for relapse. As he noted, "you may take a different way home and don't know why you turned that way or thought to take that route but it's right by where the dope boy stands. It's wild."

Jim did not yet trust himself to leave the house with cash, but other participants actively worked to reshape once-problematic relations with everyday objects. Included in Nicole's collection of photos was an image of a cell phone charger, plugged into her wall. The cord, she explained, was something that she had often appropriated as a "tie-off," helping her blood vessels to pop out enough for her to hit a vein and inject herself with heroin. Nicole described how she had once preferred the phone card over a piece of cloth or even a shoestring because it was sturdier. "This was my go-to," she said. Nowadays, Nicole used the cord to charge a 


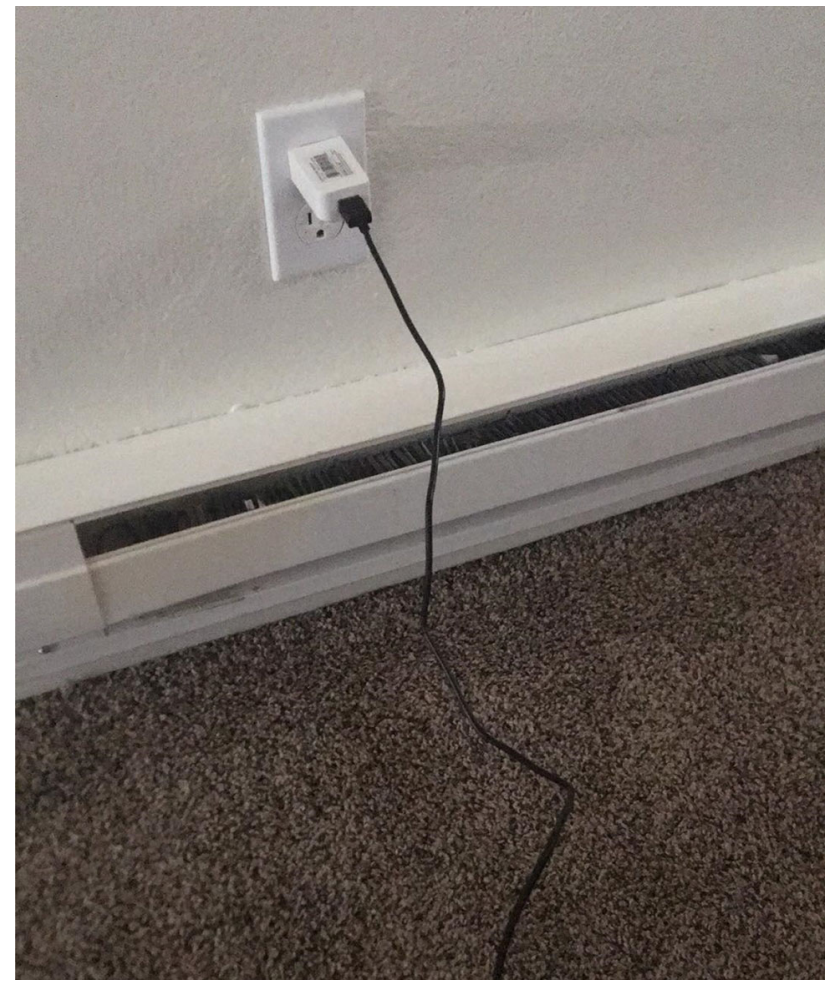

Fig. 3 Nicole: "This was my go-to"

cellular phone that she filled with pictures of her daughters, her girlfriend, the new hairstyles she was practicing on the mannequins at work. Her body had learned to associate it with new and different practices, and it was finally beginning to lose some of its past associations. But this was a process, ever unfolding. When Nicole was first released from her last period of incarceration, which had kicked off her current episode of sustained abstinence and recovery, the phone cord had been an issue for her, "A huge problem...like, Oh my God" (Fig. 3).

Yet Nicole's decision to keep her phone cord out and on display had a purpose. Her choice to capture this phone cord in a photograph was also an assertion of progress in her unfolding process of recovery. Heeding the training she had received as part of a CBT program a few months back, she sought to retrain herself to see these objects and not be triggered by them. In other words, she made a calculation: risk an initial round of triggering associations to one day be able to banish them. As she grew more secure in her recovery, this calculation was paying off.

\section{People}

While the instructions requested that participants avoid taking pictures of faces or any identifiable body parts, people were frequent subjects of photographs, 
represented through personal objects associated with them, or body parts that were not directly identifiable. Discussions of social relationships represented by these photographs generally fell into one of three categories: kin relationships (family and children/offspring), relationships with romantic partners, and relationships with friends/peers. Of these three categories, kin received the most attention, and relationships with children-biological children but also niblings and younger siblings - were articulated as both a source of pain and pride.

The two participants that had custody of their children at the time of the interview both articulated that this was a motivating factor in their lives-they could not go back to using drugs, or else they would lose them. Vivian, for instance, had lost custody of her two older daughters when she was actively using opioids. When her youngest child was born during a sustained period of recovery, she worked hard to keep him in her care. Her relapses, though short and infrequent, were terrifying. Included in her collage was a picture of her young son's toys, meant to represent a motivator in her recovery process. Speaking of her son, Vivian noted that,

He brings joy to my life and that's why I just want to get better. Because this [referring to her recent relapse] is so stupid. I can't believe I got myself into this situation. I'm like, really upset about it. And when I think about him, I think I need to be strong for him. So, I need to get my shit together.

Rather than a choice to use or not use, the calculation, for Vivian, was more complicated. In front of her son, Vivian felt a strong sense of responsibility, and the opportunity for a second chance to be a stable caregiver. However, on the weekends that her ex-boyfriend took the child, as was their custody arrangement, it was easier for Vivian to feel the pull of drug use that she knew was going on in the apartment downstairs. The object reminders of childhood - the toys, the toddler clothescarried ambivalent associations. They reminded Vivian of past mistakes and failed relationships. She was forced to calculate between the sense of relief that heroin could bring to the memories that haunted her present, and the responsibility she felt towards her son. Her relapses, when they happened, occurred whenever he was with her ex (Fig. 4).

The participants with school-aged children not in their custody frequently described conflicts with family members regarding their rights as parents. Some participants articulated a greater ambivalence regarding their relationships with their children, and what it meant for their attempts at recovery. Lexie, for instance, shared an image of a sonagram, taken when she was pregnant with her youngest son. Lexie recounted how was removed from her custody when he was an infant, and remained connected to him only through the few photos that she had managed to accumulate, including this one. Fingering the picture, Lexie explained how thoughts of her children motivated her to get her life under control, but also served as a source of shame:

[t]his picture can make me straighten up and not get high or it can make me be like oh my god...I want to go and get high because I miss him. You know what I mean?" 


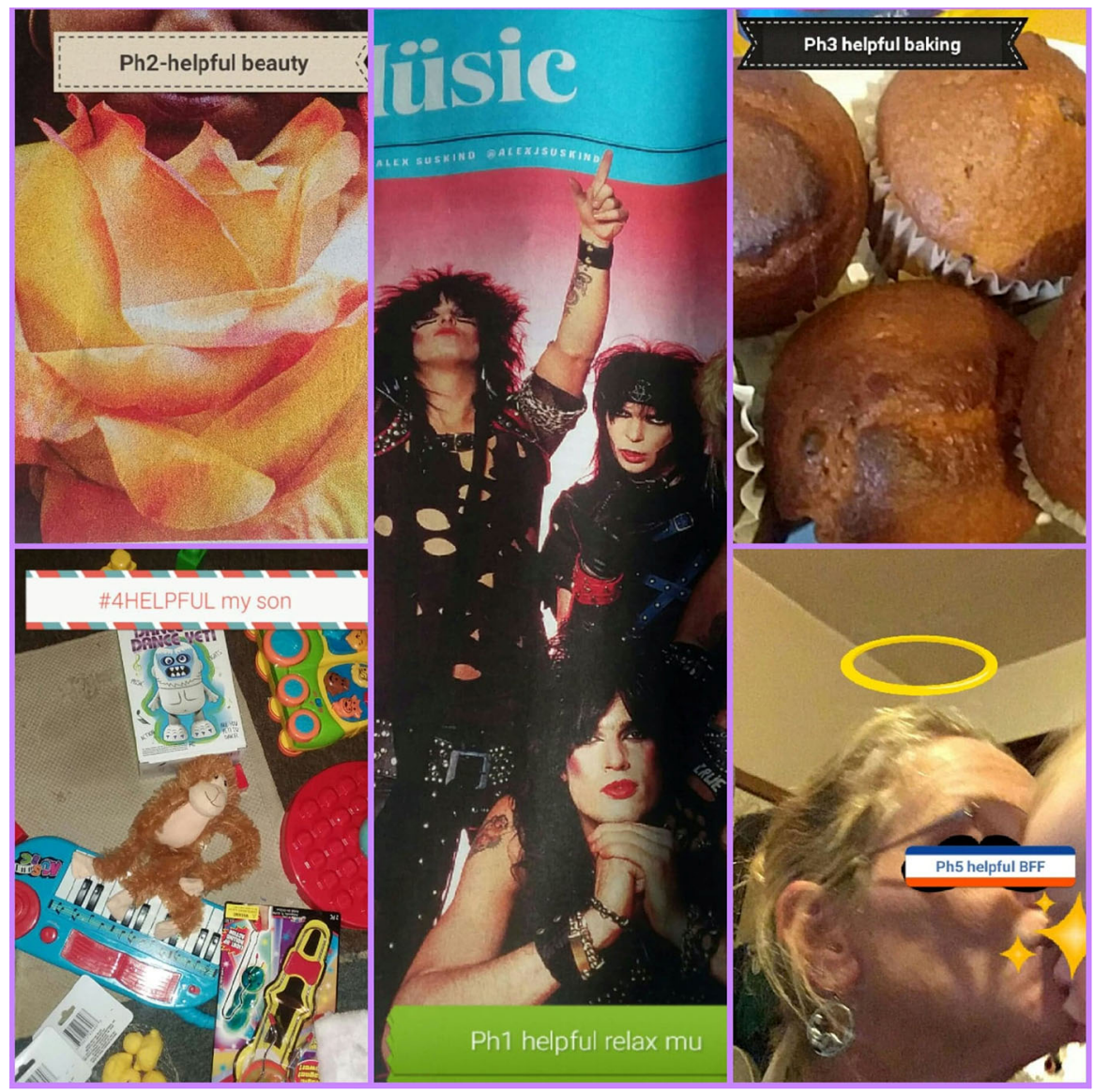

Fig. 4 Vivian's collage of motivators

Lexie, like Vivian, was forced to make complex calculations between the sense of responsibility and motivation that her children could inspire, and the feelings of shame and pain that they could also invoke. Her youngest son was now school-aged, but she had not seen him since he was an infant, a few weeks old. Nevertheless, she kept the ultrasound photo at home, keeping alive her connection to him. Looking at the photo, however, was a gamble - a calculation of hope and heartbreak. Would it make her "straighten up" or grieve? Calculations such as this were part of Lexie's everyday navigation of relations, and her efforts to get her drug use under control were shaped by them (Fig. 5).

Relationships with friends and romantic partners were also represented through photographs, although less frequently than kin relations. Romantic relationships forged during periods of drug use were consistently articulated to be barriers to recovery, for a host of reasons. Some participants described fights with romantic partners as a trigger to use drugs or to relapse, while others portrayed relationships as enabling drug use. Two participants described being hesitant to enter treatment 


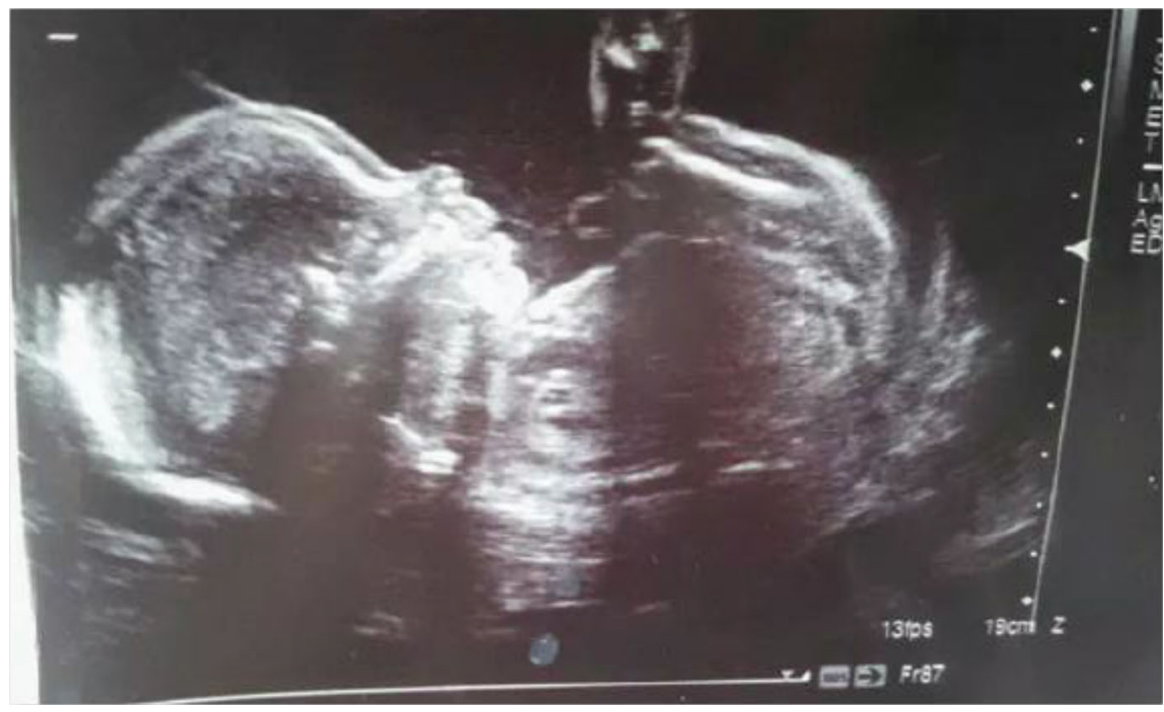

Fig. 5 Lexie: "This picture can make me straighten up and not get high or it can make me be like oh my god...I want to go and get high because I miss him. You know what I mean?”

programs because they feared what would happen to their partners if left alone. Aside from kin and romantic relationships, there was little other mention of specific social relationships, other than a few mentions of supportive friends who encouraged participants in their recovery. In a more abstract form, however, people-filled social worlds, described through photographs of places and environments, were articulated as having a profound yet ambivalent impact on unfolding experiences of recovery.

\section{Places}

Photographs of places appeared in each of the thirteen sets of images. They were often symbolic representations of particular social environments-both places that could challenge, but also places that could support and sustain recovery efforts. Place photographs could also be specific, documenting a particular building or region that was pregnant with memories or feelings that generated some sort of reckoning with the ongoing process of recovery. Both Marco and Chance took photographs of the interior of a city bus. They described how riding public transportation could challenge attempts at abstinence from opioid use, due to the presence of visibly intoxicated people, drug sales, and assorted other sensory cues that reminded them of the social worlds of illicit drugs that they were seeking to avoid. As Marco put it,

I hate being on the bus. It makes me want to get high because I've used the bus... like, going to downtown and getting off and waiting is a big problem for me. You know, because there's hella' dope boys [dealers] down there, all the 
people that I know that I got high with, that I run the streets with that I run into down there. it's just everything about it. It has relapse written on it.

Chance, on the other hand, who was more successful than Marco in avoiding opioid use, described a detailed plan in which he avoided the central bus terminal. Instead, he would get off at alternate stops and walk so he could avoid the nodes of public transportation that were most "triggering" for him. Chance's daily routines-getting to work, doctor appointments, self-help meetings-involved a calculation of interactions, resources, and time. By describing his strategy of avoiding the bus hub and associated triggers, Chance's image and its accompanying story highlight the fragility of his experience as a person newly in recovery navigating daily life. His ability to make a calculation of time, risk, and sensation, however, demonstrated a certain progress, a moving forward. This was distinct from Marco, who while acknowledging that the bus had "relapse written all over it," did not establish any particular strategies for avoiding or redirecting the triggering sensations he experienced while on public transportation (Fig. 6).

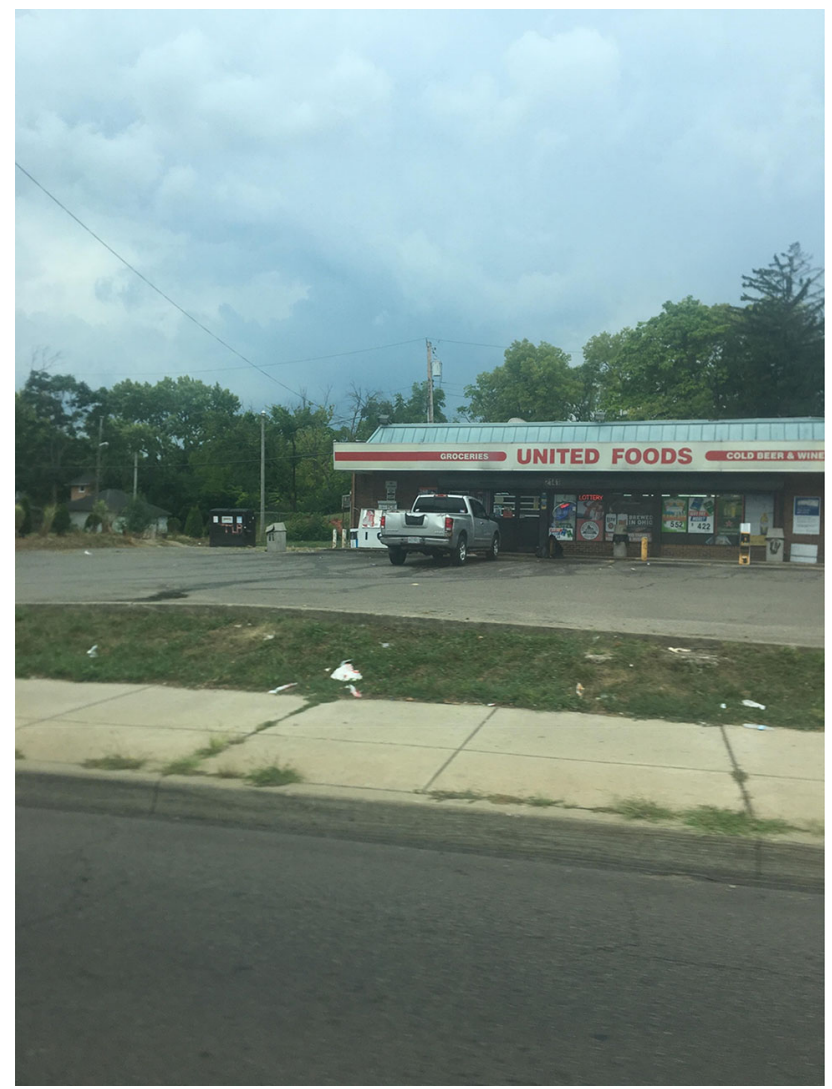

Fig. 6 Nicole: "There's not one time that I have drove by this without thinking of everything that I've done here" 
While Chance could avoid the bus terminal by walking a few extra blocks, other places were more challenging to circumvent. Nicole, who took the bus to cosmetology school each day, was forced to pass by the gas station where she used to meet her drug dealer. "There's not one time that I have drove by this," she began, holding the photograph that she took from the window of the bus on her daily commute, "without thinking of everything that I've done here". For participants who had extensive histories of drug use and had lived all their lives in the Dayton area, it was hard to find a place that did not remind them of these experiences (noted Lexie, "I feel like wherever I go it's, you know what I mean, it [opioids and other drugs]'s anywhere and everywhere".) However, some participants articulated a willingness to reframe even their understandings of these landscapes using the subtle shifts in perspective that they gained from sustained periods of recovery. Ed, for instance, captured a picture of a rainbow, and described the image in the following way (Fig. 7):

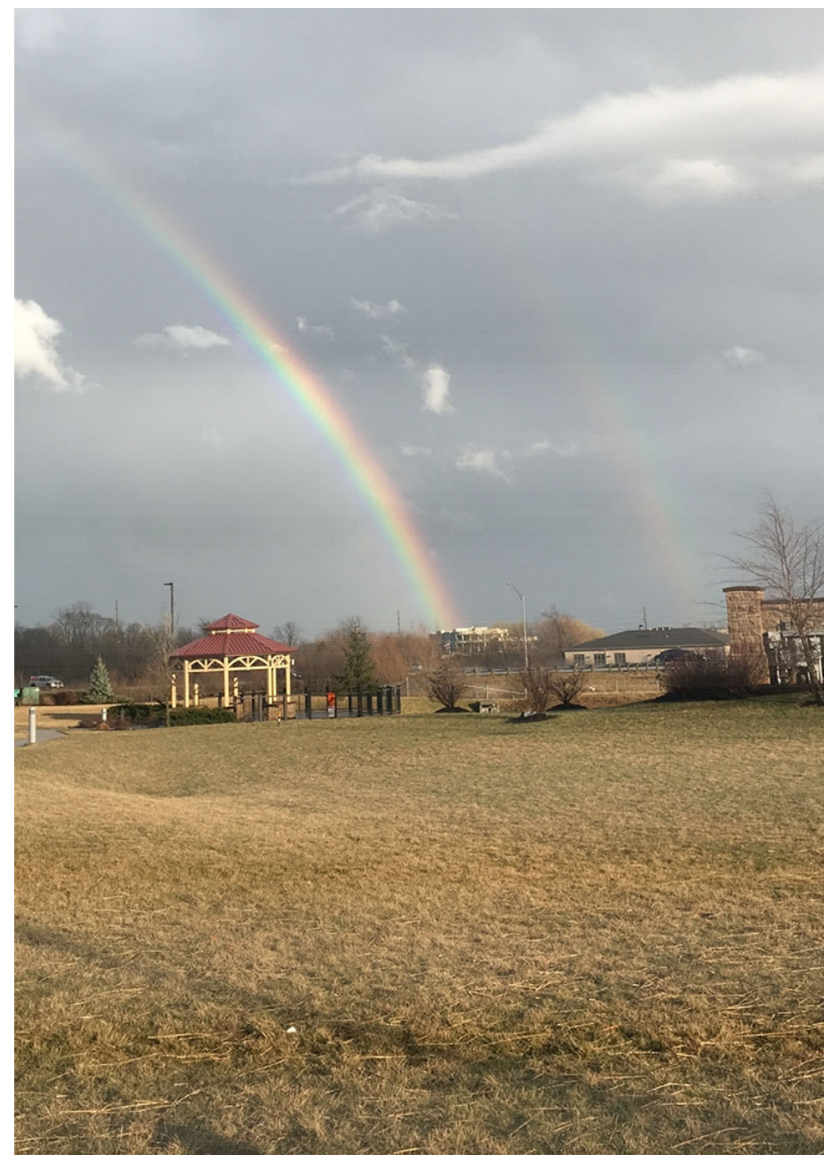

Fig. 7 Ed: "I never would have even cared to look or maybe not even noticed it if I was getting high." 
I never would have even cared to look or maybe not even noticed it if I was getting high. I like taking pictures, too, and seeing stuff and I probably, you know, wouldn't have even of thought about it twice, wouldn't even remember it if I was getting high. I would have just kept on going, not even think about it, stop, and look at it.

Photographs of places also reflected some of the structural experiences of marginalization experienced by people with histories of drug use (cf. Fast 2017). Many of the participants took photographs to represent present or past experiences of homelessness or unstable housing. A lack of stable housing often caused a greater reliance on public spaces-for rest, for shelter, and for drug use. During attempts at recovery, these same spaces were experienced by participants as pregnant with memories and associations.

Tommy took his photos after a brief stint in county jail, for a parole violation. He had been "detoxed" from heroin/NPF in jail and looked forward to being released without the anxiety of impending withdrawals. During the day, spent a lot of time walking the trail that ran alongside the Little Miami River and trying to distract

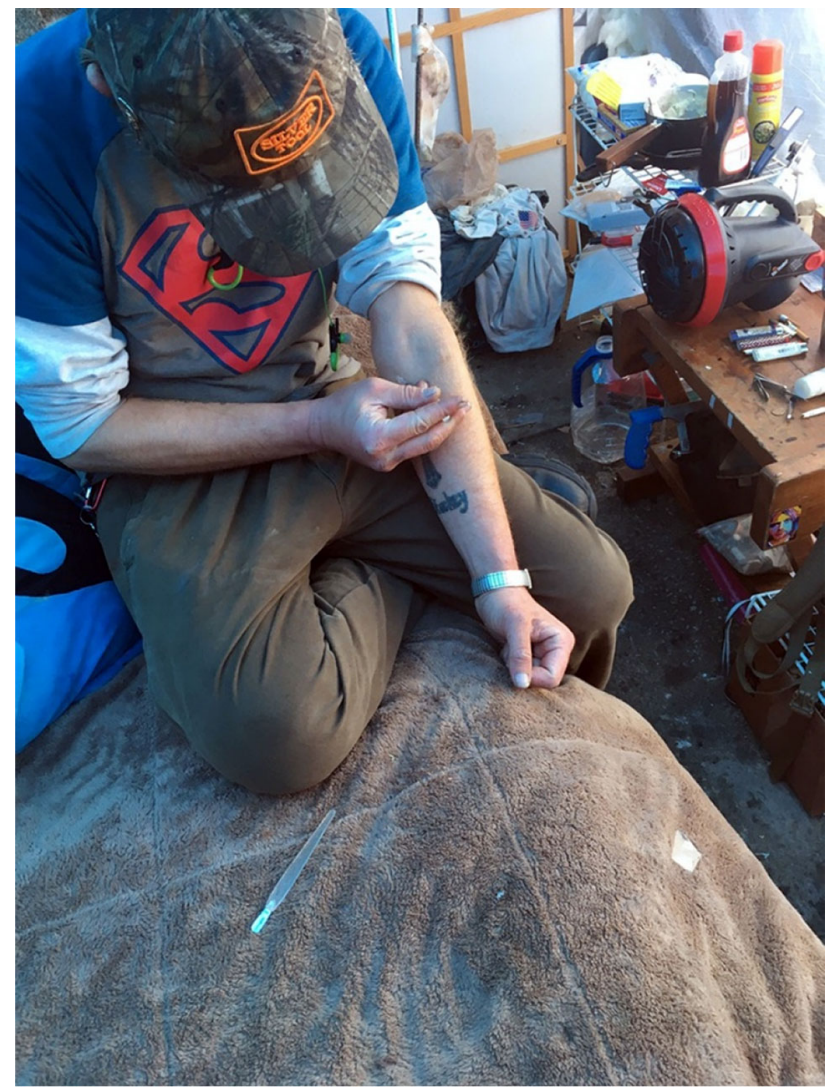

Fig. 8 Tommy: "It's like trying to go on a straight lane with bumps in the road." 
himself from wanting to get high. Nighttime, however, created new complications. For Tommy, staying at the local homeless shelter triggered intense fits of anxiety which he connected to his extensive incarceration history and the violent entanglements he associated with it. He could stay up all night, but that was only possible if he used methamphetamine, which, he admitted, made him feel "crazy". The remaining option was the makeshift home built by the side of a dumpster in the parking lot of a closed-down fast-food restaurant. The home was built by an old friend of Tommy's, someone that he had used heroin with many times before. So, he had to make a calculation of risk and benefit-which of these options would be most detrimental to his well-being, and ultimately his chances at recovery? The anxiety associated with the shelter and the paranoia brought on by methamphetamine use made the final option clear, and he sought out his old friend on the side of the dumpster (Fig. 8).

He took a photograph of the friend as he injected himself with heroin. He described this photo as a factor in the undoing of his attempt at sobriety, noting that "Living on the streets, you can't stay sober. It's impossible [...] it's like trying to go on a straight lane with bumps in the road."

\section{Discussion}

In this study, we use a critical-phenomenological analysis of participatory photographs and photo-elicitation interviews to explore attempts at, and experiences of recovery among people living with OUD. We have built on prior works of recovery by including in our sample individuals who do not consider themselves to be yet fully recovered from OUD but are actively experimenting with ways to cease or mitigate problematic drug use, testing the waters of a new way of being in the world without opioids. By including the perspectives of people across a continuum of the liminal space between chronic, problematic opioid use and abstinence from opioids (with our without the support of pharmacotherapies), we have shown the ways in which often ambivalent relations with things, people, and places can shape attempts at recovery, and must be considered in a host of everyday decisions, such as the route to take to work, what to have (or not have) in one's pocket, or what to leave out in the home.

Considering the importance of relations illuminated by the participatory and photographic nature of our materials, we suggest a reframing of recovery as a process and active practice of calculation. Following other scholars who have argued for recovery to be understood as an unfolding process of becoming (Duff 2016; Lester 2013), we build on these understanding by emphasizing practices of calibration and calculation as people attempting recovery navigate vibrant relations in their social worlds. These calculations shifted as trajectories changed over time, and relations were recalibrated to reflect evolving projects of self.

Nicole, who felt more secure in her recovery, purposely allowed herself to interface with objects-such as her phone cord-that she once considered triggering, knowing that a reframing of these relationships was crucial to the continued progress of her recovery. Jim, on the other hand, was less secure. 
His hesitation to leave the house with money in his pocket demonstrated his acute awareness of the "intangible forces" (Dennis 2016:129) that created triggering assemblages out of relations among people, places, and objects. In crafting his calculus of recovery, he cautiously calibrated elements of risk, and purposefully excluded particular objects (such as money) rather than attempt to retrain himself to relate to them in new ways.

Other participants were still testing the waters of a life without problematic opioid use and appeared less decisive in their calculations of relations. Marco and Lexie, who were enrolled in treatment programs but continued to inject heroin or fentanyl daily, both expressed a sense of ambivalence towards the relations that they identified as helpful or supportive in their efforts towards a recovery process. Marco's description of the double bind of the methadone clinic, like Lexie's ambivalent feelings towards the ultrasound photograph of her estranged son, demonstrated a calculus of relations that maintained them both in a holding pattern, testing the waters of recovery while remaining unwilling, or unable, to fully commit. In calibrating the motivating, but at the same time triggering, effects of the objects, places, and people depicted in their photographs, they remained mired in ambivalence, just as their recovery trajectories remained in a liminal state.

In emphasizing the relational nature of recovery, we build on a body of scholarship that developed the concept of recovery capital to suggest the ways in which recovery is a deeply social phenomenon. Attention to interpersonal relationships - from work to religious groups to community activism - should be an integral part of recovery efforts (Cloud and Granfield 2008; Granfield and Cloud 1999). Our findings support arguments made by proponents of the recovery capital concept, while at the same time illuminating the importance not just of the interpersonal, but also environmental and material relations in experiences of recovery (Duff 2016; Proudfoot 2019). As the ongoing crisis of drug misuse and overdose death continues to generate attention and new forms of advocacy in the realms of addiction treatment and harm reduction, it is important to not overlook the multiple relationships generated from addictions. While the disease model of addiction has been crucial in sustaining advocacy work for people living with addictions, it may also overshadow the importance of relations-with other people but also with things and places - in both perpetuating an addiction or in supporting or sustaining a recovery process. Indeed, in more carefully considering recovery as an active process and not an outcome is to attend more closely to how calculations of recovery are present in the choices and logics that guide the practices of everyday life.

The photographs taken by participants were key to illuminating the relational and unfolding nature of recovery. Prior studies have used photography as a means of understanding the experiences of people who use drugs, seeking to humanize the experience of addiction (Bourgois and Schonberg 2009; Goodman 2016), or illuminate intimate aspects of experience that are often overshadowed by standard quantitative and qualitative addiction research, such as the creation of intimate spaces in spite of violence and precarity (Syvertsen, Bazzi, and Mittal et al. 2017), or strands of hope and aspiration woven throughout experiences of marginality amidst widespread gentrification (Fast 2017). Here, photographs reveal a more 
expansive portrait of the relations shaping experiences of, or attempts at recovery, while also illuminating the complex calculations made by participants as they navigated relations with objects, people, and places in daily practice.

\section{Limitations}

This study has some limitations. It draws on a relatively small sample of interviews, and thus may not be generalizable. However, the integration of photographs, interviews, and ethnographic insights generated from the First Author's long-term engagement with all thirteen participants attempt to compensate for the small sample size with depth. Some participants may have felt limited in what they could photograph due to ethical concerns relating to the illicit nature of drug use or the vulnerability of individuals close to them. During interviews, however, the first author asked all participants what they would have liked to have photographed but were unable to due to constraints. Responses did not suggest that any new topics or themes would have emerged even if ethics were not a consideration. While photographic research with people who use drugs may itself raise some ethical concerns, participatory practices help to tip the balance of power towards participants, who can choose how they would like to represent their experiences.

\section{Conclusions}

The last time Vivian came in for an interview it was approximately 7 months after she and the first author had sat down with her photo collages. It was a gray November day, but she seemed upbeat, having just started a new job at McDonalds and moving into a new apartment in what she described as a "safer" neighborhood. She had managed to resume her regimen of buprenorphine pharmacotherapy, and continued to have primary custody of her son, who had recently turned three. She admitted to smoking crack one time the week before but had managed to stay away from heroin. Her son had accompanied her to the interview, and her love for him was palpable.

Seven months later, we learned that Vivian had overdosed in her home. Her overdose occurred during the early months of the COVID-19 pandemic, following a local increase in overdose deaths following the March 2020 stay-at-home order (PHDMC 2020). Her ex-boyfriend alerted a member of the research team to her passing, letting us know that it was an overdose that he now had full custody of their son. Beyond that, there are no details, no insights into what had spurred her to use on the day of her passing, whether she experienced a sense of isolation from the pandemic, whether she lost her job or her childcare, or what sorts of relations had shaped her mood or experience of self during her final hours. Her obituary page was filled with loving testimonials left by friends, who described her as a loyal friend and caring mother. Yet for Vivian, like for the multitudes of people struggling with SUD, recovery mode of becoming that is constantly made and remade in new contexts, including pandemics and is necessarily contingent on the relations that 
emerge as novel circumstances become a part of daily life. Did Vivian lose her job in the pandemic, and fear that she would not have enough money to support her son, or was she triggered by an influx of cash from COVID relief funding? Did her son go with his father for the weekend, prompting Vivian to decide to visit her downstairs neighbors to break up the monotony and loneliness of her quarantine? While we can know none of these things, thinking empathically about Vivian's recovery as an active calculus helps us understand how her decisions, whatever they were, became contingent on novel elements and feelings introduced to her everyday routine.

In this manner, thinking critically, phenomenologically, and through images is a means of destabilizing the very notion of "recovery" as a simple and straightforward aspirational status. Instead, this method helps us to understand recovery as a making and remaking of the self, building new relationships and new daily practices while reconciling with a past that often haunts aspects of the present. Here, we have conceptualized recovery as an active practice of calculation, as multiple and often ambivalent relations with things, people, and places are calibrated as a part of everyday routines. As such, a visual-ethnographic perspective on recovery reveals a complicated web of relations that shape local experiences of risk and harm, but also hope, allowing us to re-think community responses to issues of problematic drug use and overdose death not solely in terms addiction treatment, but through a navigation of risks and opportunities that must be recalibrated daily.

\section{Declarations}

Conflict of interest On behalf of all authors, the corresponding author states that there is no conflict of interest.

Ethical Approval This study was supported by the National Institute on Drug Abuse (NIDA) Grant: 5 R01 DA040811-03. The funding source had no further role in the study design, in the collection, analysis and interpretation of the data, in the writing of the report, or in the decision to submit the paper for publication. All procedures performed in studies involving human participants were in accordance with the ethical standards of the institutional and/or national research committee and with the 1964 Helsinki declaration and its later amendments or comparable ethical standards. Informed consent was obtained from all individual participants included in the study.

\section{References}

Abadie, Roberto, Colleen Syron, Carmen Ana Devila, Angelica Rivera-Villegas, et al.

2018 'It Gives You Nothing But It Takes Away Everything': Photo Ethnography as a Lens Onto the Experiences of People Who Inject Drugs in Puerto Rico. Medicine Anthropology Theory 5(5):71.

Agar, Michael

2003 The Story of Crack: Towards a Theory of Illicit Drug Trends. Addiction Research \& Theory 11(1):3-29.

Agar, Michael, and Heather Schacht Reisinger

2001 Using Trend Theory to Explain Heroin Use Trends. Journal of Psychoactive Drugs 33(3):203211. 
APA, American Psychiatric Association

2013 Diagnostic and Statistical Manual of Mental Disorders (DSM-5®). Washington, DC: American Psychiatric Pub.

Ashford, Robert D, Austin Brown, Tiffany Brown, Jason Callis, H. Harrington Cleveland, Emily Eisenhart, Hillary Groover, Nicholas Hayes, Teresa Johnston, Thomas Kimball, Brigitte Manteuffel, Jessica McDaniel, Lindsay Montgomery, Shane Philips, Michael Polacek, Matt Statman, Jason Whitney, et al.

2019 Defining and Operationalizing the Phenomena of Recovery: A Working Definition from the Recovery Science Research Collaborative. Addiction Research \& Theory 27(3):179-188.

Bennett, Jane

2010 Vibrant Matter. Durham: Duke University Press.

Best, David, Jane Gow, Tony Knox, Avril Taylor, Teodora Groshkova, William White, et al.

2012 Mapping the Recovery Stories of Drinkers and drug Users in Glasgow: Quality of Life and Its Associations with Measures of Recovery Capital. Drug and Alcohol Review 31(3):334-341.

Best, David, Jane Gow, Avril Taylor, Anthony Knox, William White, et al.

2011 Recovery from Heroin or Alcohol Dependence: A Qualitative Account of the Recovery Experience in Glasgow. Journal of Drug Issues 41(3):359-377.

Biernacki, Patrick

1986 Pathways from Heroin Addiction: Recovery Without Treatment. Philadelphia: Temple University Press.

Bourgois, Philippe

2003 Crack and the Political Economy of Social Suffering. Addiction Research \& Theory 11(1):3137.

Bourgois, Philippe, and Jeffrey Schonberg

2009 Righteous Dopefiend (Vol. 21). California: Univ of California Press.

Bukowski, Kate, and Stephen Buetow

2011 Making the Invisible Visible: A Photovoice Exploration of Homeless Women's Health and Lives in Central Auckland. Social Science \& Medicine 72(5):739-746.

Cabassa, Leopoldo J, Andel Nicasio, and Rob Whitley

2013 Picturing Recovery: A Photovoice Exploration of Recovery Dimensions Among People with Serious Mental Illness. Psychiatric Services 64(9):837-842.

Ciccarone, Daniel

2019 The Triple Wave Epidemic: Supply and Demand Drivers of the US Opioid Overdose Crisis. The International Journal on Drug Policy 71:183.

Cloud, William, and Robert Granfield

2008 Conceptualizing Recovery Capital: Expansion of a Theoretical Construct. Substance Use \& Misuse 43(12-13):1971-1986.

Daniulaityte, Raminta, Ramzi W Nahhas, Sydney Silverstein, Silvia Martins, Angela Zaragoza, Avery

Moeller, and Robert G Carlson

2019 Patterns of non-prescribed buprenorphine and other opioid use among individuals with opioid use disorder: A latent class analysis. Drug and alcohol dependence 204:107574.

Dennis, Fay

2016 Encountering “Triggers” Drug-Body-World Entanglements of Injecting Drug Use. Contemporary Drug Problems 43(2):126-141.

Desjarlais, Robert $\mathrm{R}$

2011 Shelter Blues: Sanity and Selfhood Among the Homeless. Philadelpiha: University of Pennsylvania Press.

Draus, Paul J, Juliette K Roddy, and Mark Greenwald

2010 A Hell of a Life: Addiction and Marginality in Post-industrial Detroit. Social \& Cultural Geography 11(7):663-680.

Duff, Cameron

2012 Accounting for Context: Exploring the Role of Objects and Spaces in the Consumption of Alcohol and Other Drugs. Social \& Cultural Geography 13(2):145-159.

Duff, Cameron

2016 Atmospheres of Recovery: Assemblages of Health. Environment and Planning A 48(1):58-74.

Fast, Danya

2017 Dream Homes and Dead Ends in the City: A Photo Essay experiment. Sociology of Health \& Illness 39(7):1134-1148. 
Franzen, Sarah, and Joey Orr

2016 Participatory Research and Visual Methods. Visual Methodologies 4(1):1-9.

Garcia, Angela

2008 The Elegiac Addict: History, Chronicity, and the Melancholic Subject. Cultural Anthropology 23(4):718-746.

Garcia, Angela

2010 The Pastoral Clinic: Addiction and Dispossession Along the Rio Grande. California: Univ of California Press.

Garriott, William, and Eugene Raikhel

2015 Addiction in the Making. Annual Review of Anthropology 44:477.

Goodman, Aaron

2016 Outcasts: Exploring Documentary Photography and Photo-Elicitation with Longterm Heroin Users. Afterimage: the Journal of Media Arts and Cultural Criticism 44(3):8-11.

Goodnough, Abby 2018 This City's Overdose Deaths Have Plunged. Can Others Learn From It? The New York Times, November 25, 2018.

Graham, Aubrey Paige

2016 Pictures and Politics: Using Co-Creative Portraits to Explore the Social Dynamics of the Eastern Democratic Republic of the Congo. Visual Methodologies 4(1):10-29.

Granfield, Robert, and William Cloud

1999 Coming Clean: Overcoming Addiction Without Treatment. New York: NYU Press.

Hansen, Helena

2018 Addicted to Christ: Remaking Men in Puerto Rican Pentecostal Drug Ministries. California: Univ of California Press.

Koob, George F, and Nora D Volkow

2016 Neurobiology of Addiction: A Neurocircuitry Analysis. The Lancet Psychiatry 3(8):760-773.

Kougiali, Zetta G, et al.

2017 Planting the Seeds of Change: Directionality in the Narrative Construction of Recovery from Addiction. Psychology \& Health 32(6):639-664.

Latour, Bruno

2005 Reassembling the Social: An Introduction to Actor-Network-Theory. Oxford: Oxford University Press.

Lester, Rebecca

2013 Back from the Edge of Existence: A Critical Anthropology of Trauma. Transcultural Psychiatry 50(5):753-762.

Linde, Charlotte

2000 The Acquisition of a Speaker by a Story: How History Becomes Memory and Identity. Ethos 28(4):608-632.

Magill, Molly, and Lara A Ray

2009 Cognitive-Behavioral Treatment with Adult Alcohol and Illicit Drug Users: A Meta-analysis of Randomized Controlled Trials. Journal of Studies on Alcohol and Drugs 70(4):516-527.

Mattingly, Cheryl

2019a Critical Phenomenology and Mental Health: Moral Experience Under Extraordinary Conditions. Ethos 47(1): 115-125.

Mattingly, Cheryl

2019b Defrosting Concepts, Destabilizing Doxa: Critical Phenomenology and the Perplexing Particular. Anthropological Theory 19(4): 415-439.

MCADAMHS, Alcohol, Drug Addiction, \& Mental Health Services - Montgomery County 2021 Substance Use Disorder Treatment.

McHugh, R Kathryn, Bridget A Hearon, and Michael W Otto

2010 Cognitive Behavioral Therapy for Substance Use Disorders. Psychiatric Clinics 33(3):511-525.

McIntosh, James, and Neil McKeganey

2000 Addicts' Narratives of Recovery from Drug Use: Constructing a Non-addict Identity. Social Science \& Medicine 50(10):1501-1510.

Mizock, Lauren, Zlatka Russinova, and Roni Shani

2014 New Roads Paved on Losses: Photovoice Perspectives About Recovery from Mental Illness. Qualitative Health Research 24(11):1481-1491.

Mol, Annemarie

2002 The Body Multiple: Ontology in Medical Practice. Durham: Duke University Press. 
Mol, Annemarie

2010 Actor-Network Theory: Sensitive Terms and Enduring Tensions. Kölner Zeitschrift für Soziologie und Sozialpsychologie. Sonderheft 50:253-269.

Mosteanu, Olimpia

2020 Landscape for a Good Home: Inhabiting Ethics in the Tenement Houses of Buenos Aires and New York City. Housing, Theory and Society 38:439.

Neale, Joanne

2016 Iterative Categorization (IC): A Systematic Technique for Analysing Qualitative Data. Addiction 111(6):1096-1106.

Neale, Joanne, Sarah Nettleton, and Lucy Pickering

2012 The Everyday Lives of Recovering Heroin Users. London: Royal Society of Arts.

Neale, Joanne, Sarah Nettleton, and Lucy Pickering

2014 Gender Sameness and Difference in Recovery from Heroin Dependence: A Qualitative Exploration. International Journal of Drug Policy 25(1):3-12.

Neale, Joanne, and Caral Stevenson

2015 Social and Recovery Capital Amongst Homeless Hostel Residents Who Use Drugs and Alcohol. International Journal of Drug Policy 26(5):475-483.

NIDA, National Institue on Drug Abuse

2018a Drug Abuse Topics: Recovery. Pp. https://www.drugabuse.gov/drug-topics/recovery.

NIDA, National Institue on Drug Abuse

2018b Understanding Drug Use and Addiction DrugFacts. https://www.drugabuse.gov/publications/ drugfacts/understanding-drug-use-addiction.

Nowinski, Joseph, Stuart Baker, and Kathleen M Carroll

1992 Twelve Step Facilitation Therapy Manual: A Clinical Research Guide for Therapists Treating Individuals with Alcohol Abuse and Dependence (Vol. 1). Darby: Diane Publishing Company.

Padilla, Mark, Armando Matiz-Reyes, José Félix Colón-Burgos, Nelson Varas-Díaz, John Vertovec, et al.

2019 Adaptation of PhotoVoice Methodology to Promote Policy Dialog Among Street-Based Drug Users in Santo Domingo, Dominican Republic. Arts \&amp; Health 11(2):147-162.

PHDMC, Public Health Dayton \& Montgomery County 2020 Overdose Deaths within Montgomery County Cities and Townships, 2020. Dayton, OH.

Proudfoot, Jesse

2019 Traumatic Landscapes: Two Geographies of Addiction. Social Science and Medicine 228(2):194-201.

Rossen, L.M., B. Bastian, M. Warner, D. Khan, and Y. Chong

2019 Drug Poisoning Mortality: United States, 1999-2017. National Center for Health Statistics.

Rui, Taniele

2014 Nas tramas do crack: etnografia da abjeção: Editora Terceiro Nome.

SAMHSA, Substance Abuse and Mental Health Services Administration

2016 What Individuals in Recovery Need to Know About Wellness. Volume Publication No. SMA16-4950. Rockville, MD: US Department of Health and Human Services.

Silverstein, Sydney M., Daniulatyte, Raminta, Miller, Shannon C., Martins, Silvia S., and Robert Carlson. 2020 On My Own Terms: Motivations for Self-treating Opioid-Use Disorder with Non-prescribed Buprenorphine. Drug and Alcohol Dependence 210: 107958.

Silverstein, Sydney M

2017 Inside a Uniform Imaginary: Gender, Politics, and Aesthetics in Peruvian Technical Education. The Journal of Latin American and Caribbean Anthropology 22(3):578-597.

Silverstein, Sydney M

2021 A Second Chance: Reenactment and Recovery Narratives in a Peruvian Drug Rehabilitation Center. Medical Anthropology Quarterly 35(2):190-208.

Silverstein, Sydney M, Raminta Daniulaityte, Silvia S Martins, Shannon C Miller, and Robert G Carlson

2019 Everything is not right anymore: Buprenorphine experiences in an era of street fentanyl. International Journal of Drug Policy 74:76-83.

Sue, Kimberly

2019 Getting Wrecked: Women, Incarceration, and the American Opioid Crisis. Volume 46: California Public Anthropology.

Syvertsen, Jennifer L, Angela Robertson Bazzi, and Maria Luisa Mittal

2017 Hope Amidst Horror: Documenting the Effects of the "War On Drugs" Among Female Sex Workers and Their Intimate Partners in Tijuana, Mexico. Medical Anthropology 36(6):566-583. 
Törrönen, Jukka, and Christoffer Tigerstedt

2018 Following the Moving and Changing Attachments and Assemblages of 'Addiction': Applying the Actor Network Approach to Autobiographies. International Journal of Drug Policy 54:60-67.

Volkow, Nora D.

2018 What Does It Mean When We Call Addiction a Brain Disorder? In Nora's Blog: National Institute on Drug Abuse.

Volkow, Nora D

2021 The Epidemic of Fentanyl Misuse and Overdoses: Challenges and Strategies. World Psychiatry 20(2):195.

White, William L

2007 Addiction Recovery: Its Definition and Conceptual Boundaries. Journal of Substance Abuse Treatment 33(3):229-241.

Winhusen, Theresa, Alexander Walley, Laura C. Fanucchi, Tim Hunt, Mike Lyons, Michelle Lofwall, Jennifer L. Brown, Patricia R. Freeman, Edward Nunes, Donna Beers, Richard Saitz, Leyla Stambaugh, Emmanuel A. Oga, Nicole Herron, Trevor Baker, Christopher D. Cook, Monica F. Roberts, Daniel P. Alford, Redonna K. Chandler, et al.

2020 The Opioid-Overdose Reduction Continuum of Care Approach (ORCCA): Evidence-Based Practices in the HEALing communities study. Drug and Alcohol Dependence 217:108325.

Zinberg, Norman E

1984 Drug, Set, and Setting: The Basis for Controlled Intoxicant Use. New Haven: Yale University Press.

Publisher's Note Springer Nature remains neutral with regard to jurisdictional claims in published maps and institutional affiliations. 